\title{
Fabrication and Surface-Modification of Silica/Gadolinium Compound/Silica Core-Shell Nanoparticles Discovered by Transmission Electron Microscopy
}

\author{
Eriko Kawamata, Tomoya Inose, Yoshio Kobayashi \\ Department of Materials Science and Engineering, Graduate School of Science and Engineering \\ Ibaraki University \\ 4-12-1 Naka-narusawa-cho, Hitachi, Ibaraki 316-8511, Japan \\ yoshio.kobayashi.yk@vc.ibaraki.ac.jp
}

\begin{abstract}
The present work describes methods for fabricating multilayered core-shell nanoparticles composed of silica $\left(\mathrm{SiO}_{2}\right)$ as a core, gadolinium compound (GdC) as an inner shell, and $\mathrm{SiO}_{2}$ as an outer shell $\left(\mathrm{SiO}_{2} / \mathrm{GdC} / \mathrm{SiO}_{2}\right)$ toward colloidally-stable, inert magnetic resonance imaging contrast agent, and for surface-modifying the $\mathrm{SiO}_{2} / \mathrm{GdC} / \mathrm{SiO}_{2}$ nanoparticles toward immobilization of functional molecules on the $\mathrm{SiO}_{2} / \mathrm{GdC} / \mathrm{SiO}_{2}$. $\mathrm{SiO}_{2}$ nanoparticles (particle size by transmission electron microscopy (TEM): 28.6 $\pm 12.6 \mathrm{~nm}$ ) were produced by a sol-gel method using tetraethylorthosilicate (TEOS) and methylamine in water/ethanol solution. GdC-coated $\mathrm{SiO}_{2}$ nanoparticles

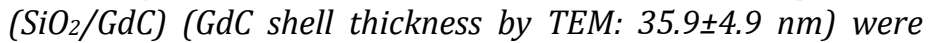
synthesized by a homogeneous precipitation method using water/propanol solution containing the $\mathrm{SiO}_{2}$ nanoparticles, $\mathrm{Gd}\left(\mathrm{NO}_{3}\right)_{3}$, urea and polyvinylpyrrolidone. Succeeding $\mathrm{SiO}_{2}$ coating of the $\mathrm{SiO}_{2} / \mathrm{GdC}$ nanaoparticles was performed by using TEOS and $\mathrm{NaOH}$ in the presence of $\mathrm{SiO}_{2} / \mathrm{GdC}$ nanoparticles. Consequently, $\mathrm{SiO}_{2} / \mathrm{GdC} / \mathrm{SiO}_{2}$ nanoparticles $\left(\mathrm{SiO}_{2}\right.$ shell thickness by TEM: $8.5 \pm 2.7 \mathrm{~nm}$ ) could be obtained. The $\mathrm{SiO}_{2} / \mathrm{GdC} / \mathrm{SiO}_{2}$ nanoparticles were successfully surface-modified by using 3aminopropyltrimethoxysilane for amination, and by followingly using succinic anhydride for carboxylation.
\end{abstract}

Keywords: Multilayer, Core-shell, Nanoparticle, Silica, Gadolinium, Sol-gel, Homogeneous precipitation, Surface-modification

(C) Copyright 2019 Authors - This is an Open Access article published under the Creative Commons Attribution License terms (http://creativecommons.org/licenses/by/3.0). Unrestricted use, distribution, and reproduction in any medium are permitted, provided the original work is properly cited.

\section{Introduction}

Because of magnetic resonance based on paramagnetism of gadolinium (Gd) ions, they function to increase contrast of images taken by a magnetic resonance imaging (MRI) technique [1]. Commerciallyavailable Gd ion-related MRI contrast agents are solutions dissolving the Gd complexes homogeneously at molecular level. The contrast agents injected into living bodies flow in living bodies, and finally are discharged out of the living bodies. Since Gd complex molecules are smaller than the particles, their velocity may be large compared to nano- or submicron particles, which provides small drag force given from fluid. Thus, the discharge for the Gd complex molecules is quick, which makes it difficult to take high contrast images for a long period.

Particles containing Gd compounds (GdC) are promising as a new MRI contrast agent. The particles, which are larger than Gd ion-related molecules, are dragged from fluid to a direction opposite to the fluid due to their projected area larger than molecules, so that they can be expected to stay in living bodies for a long period due to controlled flow of the particles in liquid. Consequently, formation of the particles containing $\mathrm{GdC}$ will increase residence time of $\mathrm{GdC}$ in the living bodies, which makes it possible to take clear MRI images for a long term. The particles are required to unaggregate in living bodies, because aggregation of the particles increases their apparent size, which prevents them from flowing in body fluid. Since surface of silica $\left(\mathrm{SiO}_{2}\right)$ 
particles prepared by a sol-gel method has a feature of colloidal stability, $\mathrm{SiO}_{2}$ particles containing $\mathrm{GdC}$ may function as the MRI contrast agent that shows long residence time and non-aggregation in living bodies. Some researchers have studied on particles composed of $\mathrm{GdC}$ as core and silica as shell [2,3]. Our research group also has reported the fabrication of core-shell nanoparticles composed of core of $\mathrm{GdC}$ and shell of $\mathrm{SiO}_{2}$ $\left(\mathrm{GdC} / \mathrm{SiO}_{2}\right)[4]$.

Because strong interaction between water protons and GdC molecules promotes MRI properties of GdC [5], the $\mathrm{GdC}$ is desired to be present on or near surface of $\mathrm{SiO}_{2}$ nanoparticles containing GdC. Accordingly, core-shell particles containing $\mathrm{GdC}$ as core are not necessarily suitable to MRI contrast agents. Then, several researchers have studied on core-shell particles composed of $\mathrm{SiO}_{2}$ as core and $\mathrm{GdC}$ as shell [6,7], in which the colloidal stability of $\mathrm{SiO}_{2}$ particles will stabilize the core-shell particles colloidally. The GdC on or near the particle surface may release free gadolinium ions through dissociation of the complexes. The release of gadolinium ions may provoke adverse reactions in some patients [8], though their toxicity is lower than that of iodine compounds. As one of methods for reducing the adverse reactions derived from $\mathrm{GdC}$, coating of $\mathrm{GdC}$ surface with materials inert to living bodies as shell can be given, because contact of the $\mathrm{GdC}$ with living bodies may be controlled with a physical barrier of the shell materials. The $\mathrm{SiO}_{2}$ is a candidate as the shell materials because of its inertness to living bodies. From this view point, our research group has reported the fabrications of core-shell nanoparticles composed of core of $\mathrm{SiO}_{2}$ and shell of $\mathrm{GdC}\left(\mathrm{SiO}_{2} / \mathrm{GdC}\right)$, and of multilayered core-shell nanoparticles composed of core of $\mathrm{SiO}_{2} / \mathrm{GdC}$ nanoparticles and shell of $\mathrm{SiO}_{2}\left(\mathrm{SiO}_{2} / \mathrm{GdC} / \mathrm{SiO}_{2}\right)$ [9]. The core-shell nanoparticles have another advantage. The GdC inside the particles can not function as the MRI contrast agent well, because it can not contact the protons in water. Thus, if the inside of the particles is replaced with core nanoparticles other than the $\mathrm{GdC}$, the replacement will decrease the production cost of MRI contrast agent nanoparticles.

To use the MRI contrast agent nanoparticles practically, functional molecules such as polyethyleneglycol and antibody protein should be immobilized onto the particles for avoiding the particles from being recognized as foreign materials in living bodies and delivering the particles to antigen proteins due to a good affinity between the antibody proteins and the antigen proteins, respectively. Prior to the immobilizations, the particles are desired to be surfacemodified with functional groups such as amino group and carboxylic group, because some functional molecules are attracted to these functional groups electro-statically or many kinds of chemicals react with the functional groups. The present paper describes methods for fabricating $\mathrm{SiO}_{2} / \mathrm{GdC} / \mathrm{SiO}_{2}$ nanoparticles, and for surface-modifying $\mathrm{SiO}_{2} / \mathrm{GdC} / \mathrm{SiO}_{2}$ nanoparticles toward a precursor of MRI contrast agent nanoparticles on which various functional molecules are immobilized

\section{Experimental}

\section{1. Chemicals}

Tetraethylorthosilicate (TEOS) (96\%), aqueous methyl amine (MA) (40\% solution) and ethanol (99.5\%) were used for preparation of silica cores and silicacoating as monomer, catalyst and solvent, respectively. Gadolinium nitrate hexahydrate $\left(\mathrm{Gd}\left(\mathrm{NO}_{3}\right)_{3} \cdot 6 \mathrm{H}_{2} \mathrm{O}\right)$ (99.5\%), urea (99.0\%), polyvinylpyrrolidone (PVP) (average molecular weight 36,000), and 1-propanol were used as chemicals for Gd shell, a precipitationinducer, a stabilizer of particles for fabrication of $\mathrm{SiO}_{2} / \mathrm{GdC}$ nanoparticles, and solvent, respectively. A sodium hydroxide $(\mathrm{NaOH})$ aqueous solution $(1 \mathrm{M})$ was used as catalyst for formation of silica shells. (3Aminopropyl)trimethoxysilane (APMS) (97\%) and succinic anhydride (SA) (98.0\%) were used for surfacemodification of particles with amino groups and carboxyl groups, respectively. The solvent dissolving SA in the surface-modification with carboxyl groups was dimethylformamide (DMF) (99.5\%). Salicylaldehyde (97.0\%) was used for confirming the presence of amino groups in particle colloid solutions. The PVP and the APMS were purchased from Nacalai Tesque Ltd. (Kyoto, Japan) and Sigma-Aldrich Co. LLC (St. Louis, USA), respectively, all the other chemicals were purchased from Wako Pure Chemicals Ltd. (Osaka, Japan). All chemicals were used as received. Water that was ionexchanged and distilled with Shimadzu SWAC-500 was used in all the preparations.

\section{2. Preparation of nanoparticles}

A colloid solution of $\mathrm{SiO}_{2}$ nanoparticles was prepared as follows. A solution of TEOS and ethanol was added to a solution of MA, water and ethanol under stirring in a hermetically sealed flask with a magnetic stirrer. The reaction temperature and time were $35^{\circ} \mathrm{C}$ and $24 \mathrm{~h}$, respectively. Initial concentrations of TEOS, $\mathrm{H}_{2} \mathrm{O}$ and MA were $0.2,20$, and $0.018 \mathrm{M}$, respectively. The silica nanoparticles were washed by repeating 

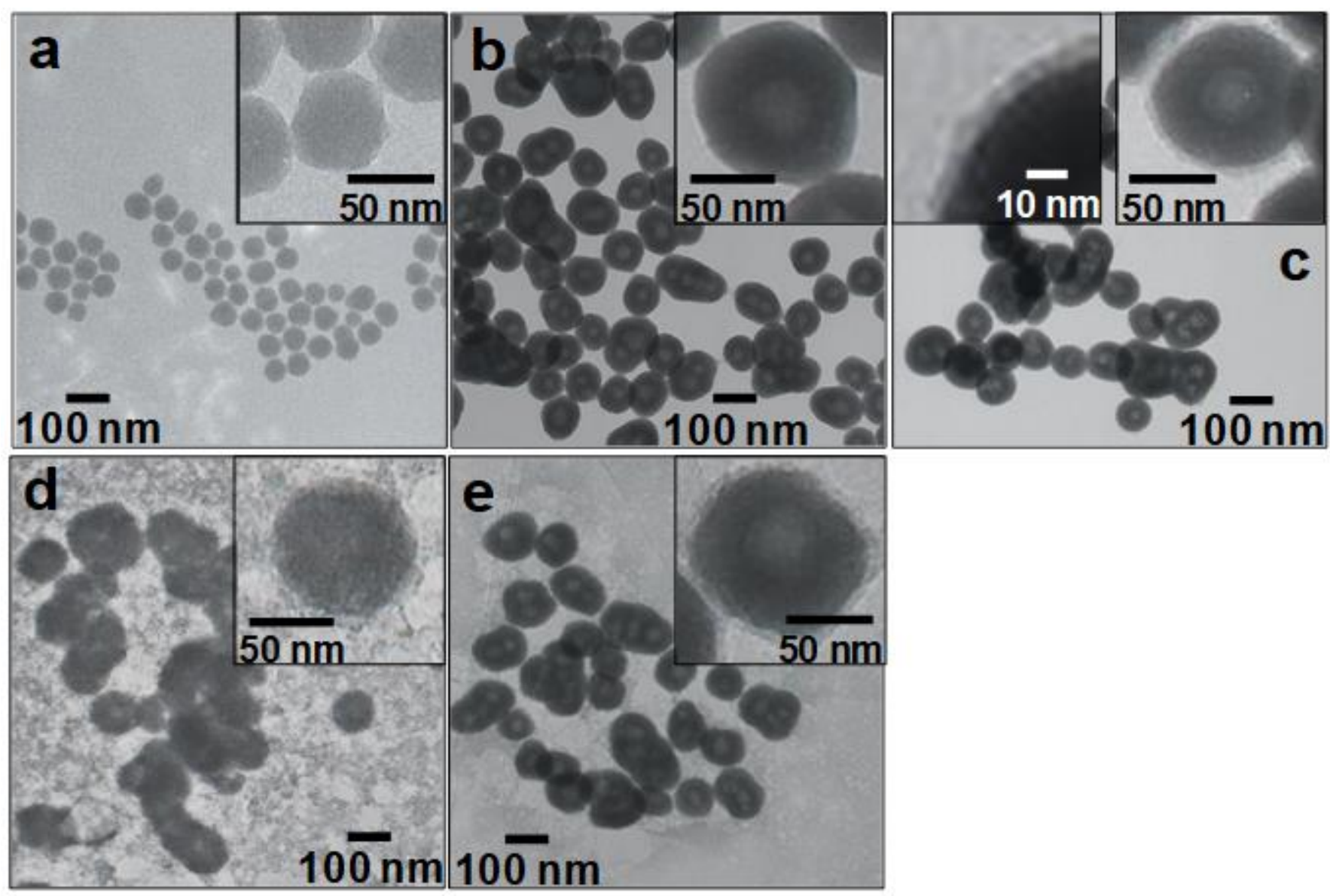

Figure 1. TEM images of (a) $\mathrm{SiO}_{2}$, (b) $\mathrm{SiO}_{2} / \mathrm{GdC}$, (c) $\mathrm{SiO}_{2} / \mathrm{GdC} / \mathrm{SiO}_{2}$, (d) $\mathrm{SiO}_{2} / \mathrm{GdC} / \mathrm{SiO}_{2}-\mathrm{NH}_{2}$, (e) $\mathrm{SiO}_{2} / \mathrm{GdC} / \mathrm{SiO}_{2}-\mathrm{COOH}$.

centrifugation, removal of supernatant, addition of the water and sonication over three times.

A colloid solution of $\mathrm{SiO}_{2} / \mathrm{GdC}$ nanoparticles was prepared as follows. The colloid solution of washed $\mathrm{SiO}_{2}$ nanoparticles and PVP dissolved in 1-propanol were added to a water/1-propanol solution, and the mixture was aged for $24 \mathrm{~h}$ at room temperature under stirring in a hermetically sealed flask with a magnetic stirrer. A urea aqueous solution was added to the aged mixture, and then $\mathrm{pH}$ of the mixture was adjusted to 5 by adding nitric acid. $\mathrm{A} \mathrm{Gd}\left(\mathrm{NO}_{3}\right)_{3}$ aqueous solution was added to the mixture. The mixture was aged for $3 \mathrm{~h}$ at $80^{\circ} \mathrm{C}$ under stirring. Initial concentrations were $0.001 \mathrm{vol} \% \mathrm{SiO}_{2}, 1$ g/L PVP, $0.5 \mathrm{M}$ urea and $0.001 \mathrm{M} \mathrm{Gd}\left(\mathrm{NO}_{3}\right)_{3}$, and a volume ratio of water : 1 -propanol was $1: 1$.

A colloid solution of $\mathrm{SiO}_{2} / \mathrm{GdC} / \mathrm{SiO}_{2}$ nanoparticles was prepared as follows. The TEOS and the $\mathrm{NaOH}$ aqueous solution were added to the as-prepared colloid solution of $\mathrm{SiO}_{2} / \mathrm{GdC}$ nanoparticles under stirring in a hermetically sealed flask with a magnetic stirrer. The reaction temperature and time were $35^{\circ} \mathrm{C}$ and $24 \mathrm{~h}$, respectively. Initial concentrations of TEOS and $\mathrm{NaOH}$ were 0.013 and $0.002 \mathrm{M}$, respectively.

\section{3. Surface-modification of nanoparticles}

The $\mathrm{SiO}_{2} / \mathrm{GdC} / \mathrm{SiO}_{2}$ nanoparticles were surfacemodified with amino groups $\left(\mathrm{SiO}_{2} / \mathrm{GdC} / \mathrm{SiO}_{2}-\mathrm{NH}_{2}\right)$ as follows. The APMS was added to the as-prepared colloid solution of $\mathrm{SiO}_{2} / \mathrm{GdC} / \mathrm{SiO}_{2}$ nanoparticles. The reaction temperature and time were $35^{\circ} \mathrm{C}$ and $24 \mathrm{~h}$, respectively. An initial APMS concentration was $0.03 \mathrm{M}$. The $\mathrm{SiO}_{2} / \mathrm{GdC} / \mathrm{SiO}_{2}-\mathrm{NH}_{2}$ nanoparticles were washed by repeating centrifugation, removal of supernatant, addition of solvent and sonication over two times. The solvents used in the second and the third washing processes were 1-propanol and DMF, respectively, which provided the replacement of solvent of colloid solution with DMF. 


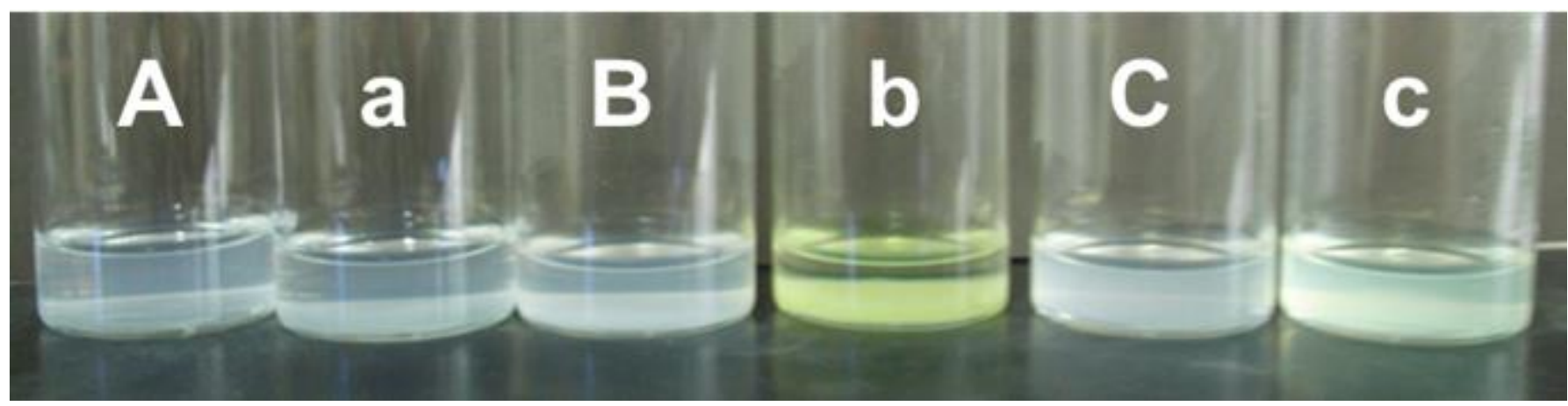

Figure 2. Photographs of various colloid solutions. (A) and (a): $\mathrm{SiO}_{2} / \mathrm{GdC}_{\mathrm{SiO}}$. (B) and (b): $\mathrm{SiO}_{2} / \mathrm{GdC}_{\mathrm{SiO}}-\mathrm{NH}_{2}$. (C) and (c): $\mathrm{SiO}_{2} / \mathrm{GdC}_{\mathrm{SiO}}-\mathrm{COOH}$. The samples (A)-(C) and (a)-(c) were prior to and after the addition of salicylaldehyde, respectively.

According to the reference [10], the amino groups on $\mathrm{SiO}_{2} / \mathrm{GdC} / \mathrm{SiO}_{2}-\mathrm{NH}_{2}$ nanoparticles were transformed to carboxyl groups $\left(\mathrm{SiO}_{2} / \mathrm{GdC} / \mathrm{SiO}_{2}-\mathrm{COOH}\right)$ as follows. The SA dissolved in DMF was added to the colloid solution of washed $\mathrm{SiO}_{2} / \mathrm{GdC} / \mathrm{SiO}_{2}-\mathrm{NH}_{2}$ nanoparticles at $35^{\circ} \mathrm{C}$. An initial SA concentration was $0.05 \mathrm{M}$. After $24 \mathrm{~h}$, the $\mathrm{SiO}_{2} / \mathrm{GdC} / \mathrm{SiO}_{2}-\mathrm{COOH}$ particles were washed by repeating centrifugation, removal of supernatant, addition of water and sonication over three times, which provided the replacement of solvent of colloid solution with water.

\section{4. Characterization}

Morphology of the particles was investigated by transmission electron microscopy (TEM). TEM was performed with a JEOL JEM-2000FX II microscope operating at $200 \mathrm{kV}$. Samples for TEM were prepared by dropping and evaporating the nanoparticle suspensions on a collodion-coated copper grid. Dozens of particle diameters in TEM images were measured to determine volume-averaged particle size, $d_{v}$, and standard deviation of particle size distribution, $\sigma$, defined by the following equations.

$$
\begin{aligned}
& d_{V}=\left(\sum n_{i} d_{i}^{3} / n_{i}\right)^{1 / 3} \\
& \sigma=\left(\sum\left(d_{i}-d_{V}\right)^{2} / \sum n_{i}\right)^{1 / 2}
\end{aligned}
$$

where $n_{i}$ is the number of particles with a size of $d_{i}$. The measurement of particle diameter was performed by using a Mitsutoyo CD-15AX digimatic caliper. The presence of amino groups in particle colloid solutions was confirmed by yellowish coloration provided by a reaction between salicylaldehyde and amino group [11].

\section{Results and Discussion}

\section{1. Morphology of nanoparticles}

The colloid solution of $\mathrm{SiO}_{2}$ nanoparticles was prepared by a sol-gel method using TEOS as a $\mathrm{SiO}_{2}$ source and MA as a catalyst. Fig. 1 (a) shows a TEM image of the $\mathrm{SiO}_{2}$ nanoparticles. The silica nanoparticles were quasi spherical and were colloidally stable. They had an average size of $28.6 \pm 12.6 \mathrm{~nm}$ by TEM. The $\mathrm{SiO}_{2} / \mathrm{GdC}$ nanoparticles exhibited no aggregation during the GdCcoating of $\mathrm{SiO}_{2}$ nanoparticles, which indicated that colloidal stability of $\mathrm{SiO}_{2}$ nanoparticles prevented generation of aggregation.

The GdC-coating of $\mathrm{SiO}_{2}$ nanoparticles, or fabrication of $\mathrm{SiO}_{2} / \mathrm{GdC}$ nanoparticles was performed by a homogeneous precipitation method in the presence of the washed silica nanoparticles. Fig. 1 (b) shows a TEM image of $\mathrm{SiO}_{2} / \mathrm{GdC}$ nanoparticles. The $\mathrm{SiO}_{2}$ nanoparticles were coated with uniform GdC shell. An average particle size and an average shell thickness were 107.0 \pm 23.0 and $35.9 \pm 4.9 \mathrm{~nm}$, respectively, by TEM. There was neither uncoated $\mathrm{SiO}_{2}$ nanoparticles nor core-free particles.

The $\mathrm{SiO}_{2}$-coating of $\mathrm{SiO}_{2} / \mathrm{GdC}$ nanoparticles, or fabrication of $\mathrm{SiO}_{2} / \mathrm{GdC} / \mathrm{SiO}_{2}$ nanoparticles was performed by a sol-gel method using TEOS as a $\mathrm{SiO}_{2}$ source and $\mathrm{NaOH}$ as a catalyst. Fig. 1 (c) shows a TEM image of $\mathrm{SiO}_{2} / \mathrm{GdC} / \mathrm{SiO}_{2}$ nanoparticles. Prior to the TEM observation, the nanoparticles were washed by repeating centrifugation, removal of supernatant, addition of the water and sonication over three times. Only multilayered core-shell particles were observed, and there was neither $\mathrm{SiO}_{2} / \mathrm{GdC}$ core-free silica nor $\mathrm{SiO}_{2}$ shell-free $\mathrm{GdC} / \mathrm{SiO}_{2}$ nanoparticles. An average particle size was $119.0 \pm 39.0 \mathrm{~nm}$ by TEM. An average $\mathrm{SiO}_{2}$ shell thickness was $8.5 \pm 2.7 \mathrm{~nm}$, according to a high magnification image (a left inset of Fig. 1 (c)). It was 
confirmed by naked eye that no sedimentation took place for the $\mathrm{SiO}_{2} / \mathrm{GdC} / \mathrm{SiO}_{2}$ nanoparticle colloid solution. This observation indicated that the $\mathrm{SiO}_{2}$ shell contributed to their colloidal stability.

\section{2. Surface-modification}

The $\mathrm{SiO}_{2} / \mathrm{GdC} / \mathrm{SiO}_{2}$ nanoparticles were surfacemodified with amino groups by a reaction between an alkoxide group of APMS and hydroxide groups of the $\mathrm{SiO}_{2}$ surface on $\mathrm{SiO}_{2} / \mathrm{GdC} / \mathrm{SiO}_{2}$ nanoparticles. Fig. 1 (d) shows a TEM image of $\mathrm{SiO}_{2} / \mathrm{GdC} / \mathrm{SiO}_{2}-\mathrm{NH}_{2}$ nanoparticles. Their multilayered core-shell structure of $\mathrm{SiO}_{2} / \mathrm{GdC} / \mathrm{SiO}_{2}$ nanoparticles was not damaged even with the surfacemodification process using APMS. Many gel networks were also generated. Since the as-prepared $\mathrm{SiO}_{2} / \mathrm{GdC} / \mathrm{SiO}_{2}$ nanoparticles were used for the surfacemodification, unreacted TEOS that did not form the $\mathrm{SiO}_{2}$ shells had might been left in the colloid solution. Probably, $\mathrm{SiO}_{2}$ nuclei were generated through hydrolysis and condensation of alkoxide groups of TEOS. Generation of silanol groups through the hydrolysis probably increased the ionic strength. Increased ionic strength has been reported to compress the double layer of colloidal particles [12]. The generation of silanol groups therefore decreased the double-layer repulsion between the nuclei. The increased ionic strength was thus primarily responsible for the aggregation and growth of nuclei in the present system, which formed the gel networks. A reaction between salicylaldehyde and amino group provides yellowish coloration of solution [11]. In the present work, the presence of amino groups in solutions was confirmed by the yellowish coloration. Figs. 2 (B) and (b) shows photographs of the $\mathrm{SiO}_{2} / \mathrm{GdC} / \mathrm{SiO}_{2}-\mathrm{NH}_{2}$ nanoparticle colloid solutions prior to and after the addition of salicylaldehyde. The color of the colloid solution turned yellowish after the addition. In the case of the $\mathrm{SiO}_{2} / \mathrm{GdC} / \mathrm{SiO}_{2}$ nanoparticles, no color change took place, as shown in Figs. 2 (A) and (a). Probably, the color change took place by a reaction between salicylaldehyde and amino group. Accordingly, the color change confirmed that amino groups were introduced on the $\mathrm{SiO}_{2} / \mathrm{GdC} / \mathrm{SiO}_{2}$ particle surface, or the $\mathrm{SiO}_{2} / \mathrm{GdC} / \mathrm{SiO}_{2}$ particle surface was successfully surfacemodified with amino groups with the amination process.

The amino groups on $\mathrm{SiO}_{2} / \mathrm{GdC} / \mathrm{SiO}_{2}-\mathrm{NH}_{2}$ nanoparticles were transformed to carboxyl groups by a reaction between a functional group of $\mathrm{SA}$ and the amino group on $\mathrm{SiO}_{2} / \mathrm{GdC} / \mathrm{SiO}_{2}-\mathrm{NH}_{2}$ nanoparticles, so that the particles were expected to be surface-modified with carboxyl groups. Fig. 1 (e) shows a TEM image of
$\mathrm{SiO}_{2} / \mathrm{GdC} / \mathrm{SiO}_{2}-\mathrm{COOH}$ nanoparticles. Their multilayered core-shell structure of $\mathrm{SiO}_{2} / \mathrm{GdC} / \mathrm{SiO}_{2}-\mathrm{NH}_{2}$ nanoparticles was not damaged even with the surface-modification process using SA. The amount of the gel network remarkably diminished compared to the $\mathrm{SiO}_{2} / \mathrm{GdC} / \mathrm{SiO}_{2}-$ $\mathrm{NH}_{2}$. Its weight was so light compared with the $\mathrm{SiO}_{2} / \mathrm{GdC} / \mathrm{SiO}_{2}-\mathrm{COOH}$ nanoparticles that some of the gel networks did not sediment with the centrifugation process. Consequently, the repeated washing process gradually removed the non-sedimenting gel networks. Figs. 2 (C) and (c) shows photographs of the $\mathrm{SiO}_{2} / \mathrm{GdC} / \mathrm{SiO}_{2}-\mathrm{COOH}$ nanoparticle colloid solutions prior to and after the addition of salicylaldehyde. The color of the colloid solution turned yellowish after the addition. The color change was slighter than that for $\mathrm{SiO}_{2} / \mathrm{GdC} / \mathrm{SiO}_{2}-\mathrm{NH}_{2}$ nanoparticles. The amino groups were transformed to carboxyl groups by a reaction between the functional groups of $\mathrm{SA}$ and the amino groups on $\mathrm{SiO}_{2} / \mathrm{GdC} / \mathrm{SiO}_{2}-\mathrm{NH}_{2}$ nanoparticles, which reduced the amino groups on particles. The reduction provided the slight color change, which indicated successful introduction of carboxyl groups onto particles, or surface-modification of particles with carboxyl groups.

\section{Conclusion}

Fabrication of multilayered $\mathrm{SiO}_{2} / \mathrm{GdC} / \mathrm{SiO}_{2}$ coreshell nanoparticles and surface-modification of the multilayered core-shell nanoparticles have been performed toward colloidally-stable, inert magnetic resonance imaging contrast agent. The $\mathrm{SiO}_{2}$ nanoparticles with the size of $28.6 \pm 12.6 \mathrm{~nm}$ (by TEM) fabricated through the sol-gel method were coated with GdC shells by means of the homogeneous precipitation method with the aid of stabilizer PVP, which produced the $\mathrm{SiO}_{2} / \mathrm{GdC}$ nanoparticles that had the average $\mathrm{GdC}$ shell thickness of $35.9 \pm 4.9 \mathrm{~nm}$ (by TEM). The $\mathrm{SiO}_{2} / \mathrm{GdC}$ nanoparticles were coated with $\mathrm{SiO}_{2}$ shells by the sol-gel method using the as-prepared $\mathrm{SiO}_{2} / \mathrm{GdC}$ nanoparticle colloid solution, which formed the $\mathrm{SiO}_{2} / \mathrm{GdC} / \mathrm{SiO}_{2}$ nanoparticles that had the average $\mathrm{SiO}_{2}$ shell thickness of $8.5 \pm 2.7 \mathrm{~nm}$ (by TEM). The $\mathrm{SiO}_{2} / \mathrm{GdC} / \mathrm{SiO}_{2}$ nanoparticle surface was aminated with APMS, and the amino groups of nanoparticle surfaces were transformed to carboxyl groups with $\mathrm{SA}$, which aimed immobilization of functional molecules on the $\mathrm{SiO}_{2} / \mathrm{GdC} / \mathrm{SiO}_{2}$ core-shell nanoparticles. 


\section{References}

[1] L. Telgmann, M. Sperling and U. Karst, "Determination of gadolinium-based MRI contrast agents in biological and environmental samples: A review," Anal. Chim. Acta, vol. 764, pp. 1-16, 2013.

[2] K. Kubasiewicz, M. Runowski, S. Lis and Agata Szczeszak, "Synthesis, structural and spectroscopic studies on $\mathrm{GdBO}_{3}: \mathrm{Yb}^{3+} / \mathrm{Tb}^{3+} @ \mathrm{SiO}_{2}$ core-shell nanostructures," J. Rare Earth, vol. 33, pp. 1148-1154, 2015.

[3] S. Kumar, V. K. Meena, P. P. Hazarib and R. K. Sharma, "FITC-Dextran entrapped and silica coated gadolinium oxide nanoparticles for synchronous optical and magnetic resonance imaging applications", Int. J. Pharmaceut., vol. 506, pp. 242-252, 2016.

[4] H. Morimoto, M. Minato, T. Nakagawa, M. Sato, Y. Kobayashi, K. Gonda, M. Takeda, N. Ohuchi and N. Suzuki, "X-ray imaging of newly-developed gadolinium compound/silica core-shell particles", J. Sol-Gel Sci. Technol., vol. 59, pp. 650-657, 2011.

[5] R. Artali, G. Bombieri, G. B. Giovenzana, M. Galli, L. Lattuada and F. Meneghetti, "Preparation, crystallographic and theoretical study on a bifunctional Gd-AAZTA derivative as potential MRI contrast agent precursor," Inorg. Chim. Acta, vol. 407, pp. 306-312, 2013.

[6] V. Feldmann, J. Engelmann, S. Gottschalk and H. A. Mayer, "Synthesis, characterization and examination of Gd[DO3A-hexylamine]-functionalized silica nanoparticles as contrast agent for MRI-applications", J. Colloid Interface Sci., vol. 366, pp. 70-79, 2012.

[7] F. Liu, X. He, L. Liu, H. You, H. Zhang and Z. Wang, "Conjugation of $\mathrm{NaGdF}_{4}$ upconverting nanoparticles on silica nanospheres as contrast agents for multimodality imaging”, Biomater., vol. 34, pp. 5218-5225, 2013.

[8] G. Marshall and C. Kasap, “Adverse events caused by MRI contrast agents: implications for radiographers who inject", Radiography, vol. 18, pp. 132-136, 2012.

[9] Y. Kobayashi, J. Imai, D. Nagao, M. Takeda, N. Ohuchi, A. Kasuya and M. Konno, "Preparation of multilayered silica-Gd-silica core-shell particles and their magnetic resonance images," Colloids Sur. A, vol. 308, pp. 14-19, 2007.

[10] Y. An, M. Chen, Q. Xue and W. Liu, "Preparation and self-assembly of carboxylic acid-functionalized silica," J. Colloid Interface Sci., vol. 311, 507-513, 2007.

[11] F. Cuoq, A. Masion, J. Labille, J. Rose, F. Ziarelli, B. Prelot, J.-Y. Bottero, "Preparation of amino- functionalized silica in aqueous conditions," Appl, Surf, Sci., vol. 266, pp. 155-160 (2013).

[12] K. Dimic-Misic, M. Hummel, J. Paltakari, H. Sixta, T. Maloney and P. Gane, "From colloidal spheres to nanofibrils: extensional flow properties of mineral pigment and mixtures with micro and nanofibrils under progressive double layer suppression," $J$. Colloid Interface Sci., vol. 446, pp. 31-43, 2015. 